doi:10.18411/ spub-3-2018-06

idsp: 000001: spub-3-2018-06

\title{
ТОЛПЕГИНА О.А. ОСОБЕННОСТИ ПРИМЕНЕНИЯ ПОНЯТИЙНОГО АППАРАТА В НЕСОСТОЯТЕЛЬНОСТИ И БАНКРОТСТВЕ
}

Российская Академия народного хозяйства и государственной службы при Президенте РФ (Россия, Москва)

\begin{abstract}
АННОТАЦИЯ
Авторское исследование проблемы неопределенности терминологического аппарата в обосновании кризисных тенденций развития, несостоятельности и банкротства субъектов хозяйствования позволяет системно подойти к пониманию и изучению кризисных состояний, степени их разрушенного воздействия для обоснования и своевременного принятия эффективных антикризисных управленческих решений. В статье проводится понятийный анализ терминов «кризис организации», «неплатежеспособность», «несостоятельность», «банкротство», рассмотренных в работах разных исследователей. Предлагаются авторские уточнения в их определении с учетом установленной последовательности нарастания разрушительных влияний факторов риска и их взаимной связи.
\end{abstract}

Ключевые слова:кризис, неплатежеспособность, несостоятельность, банкротство, антикризисное управление, юридический и экономический аспект банкротства

\section{TOLPEGINA O. \\ FEATURES OF THE CONCEPTUAL APPARATUS IN INSOLVENCY AND BANKRUPTCY}

Russian presidential Academy of national economy and public administration

(Russia, Moscow)

\begin{abstract}
The author's study of the issues of ambiguity of terminology in the rationale of the crisis tendencies of development, the insolvency and bankruptcy of business entities allows us to systematically approach the understanding of the study of the crisis States, the extent of their influence destroyed for justification and timely adoption of effective anti-crisis management decisions. The article presents a conceptual analysis of the interpretations of the terms "crisis of the organization", "insolvency", "insolvency", "bankruptcy", considered in the works of various researchers. The author's refinements in their definition are offered taking into account the established sequence of growth of destructive influences of risk factors and their mutual connection.
\end{abstract}

Keywords: crisis, insolvency, insolvency, bankruptcy, crisis management, legal and economic aspects of bankruptcy.

\section{ВВЕДЕНИЕ}

Острота проблемы в условиях кризиса, несостоятельности, банкротства организаций, связанной с причинами возникновения разрушительных тенденций, 
возможными последствиями со временем приобретает все большую социальноэкономическую значимость и злободневность, особенно в области определения путей преодоления негативных процессов, восстановления делового потенциала субъекта хозяйствования. Эффективное управление кризисными процессами требует глубокого понимания и осмысления используемой терминологии для обозначения деструктивных явлений. Обоснование понятийного аппарата также необходимо в связи с отсутствием единого подхода к определению и практики использования понятий «кризис», «несостоятельность», «банкротство» путем дифференциации и уточнения точек зрения на исследуемую проблему.

\section{1. Подходы к оценке разграничения понятий «кризис» и «банкротство»}

Наиболее общим является понятие «кризис», как неотъемлемая характеристика любого общества, как явление рыночной экономики и развитие любой системы: организации, вида экономической деятельности, страны, группы стран, мировой экономики. [Вайсблат Б.И., Любушин Н.П, 2013].

Под определением «кризис» в отношении предприятий понимается такая экономическая ситуация, которая характеризуется застоем, трудностью роста, проблемами развития [Маренков Н.Л., 2004]. В кризисные периоды наибольшую опасность для предприятия представляет разрушение его потенциала: инновационного, производственного, технологического, научно-технического и кадрового, как главных факторов жизнедеятельности предприятия и его возможностей [Хрусталев Е.Ю., 2010]. Кризис на предприятии - это прежде всего процесс негативных изменений, происходящий внутри хозяйствующего субъекта.

Кризис, исходя из проблематики его возникновения, может принимать форму стратегического кризиса, результатов деятельности, кризиса ликвидности

Кризис стратегического развития- это кризис роста. Его правомерно сравнивать с острым, глубоким кризисом, который затрагивает все направления деятельности предприятия, влечет за собой падение показателей эффективности, приводит к снижению или полной исчерпанности возможностей дальнейшего развития. Характерными его проявлениями являются стагнация, упадок.

Кризис развития ( на стадии рождения, роста, зрелости, старения). Каждая фаза развития бизнеса характеризуется свойственными ей особенностями, решаемыми задачами, стоящими перед собственниками и соответствующими различными рисками. Кризис жизненного цикла заключается в определенной закономерности проявления спада и подъема, в периодичности возникновения кризисных ситуаций, их продолжительности, в нарастании кризисных явлений вплоть до наступления банкротства, например: кризис компетенции, кризис координации, кризис контроля, бюрократии, кризис бизнес-идей или кризис синергии [Адизес И.К., 2007]

Кризис ликвидности. Начальными признаками кризиса ликвидности являются разбалансированность денежных потоков, и как следствие неспособность организации отвечать по своим обязательствам по мере их наступления, в результате чего возникает угроза потери платежеспособности.

Кризис результатов финансово-хозяйственной деятельности. Основные проявления этого кризиса заключаются в неизменном снижении оборачиваемости капитала, в падении прибыли, рентабельности, в постоянном уменьшении собственного капитала и снижении эффективности его использования, в росте затрат на привлечение источников финансирования текущей деятельности, что приводит к получению убытка.

Управленческий кризис- кризис в системе менеджмента. Связан с неэффективным управлением, с ошибками и неточностями в решении вопросов управления. 
Видовое разнообразие кризисов не ограничивается названными выше. Кризисные процессы могут проявляться в различных сферах деятельности организации: технологической (производственной), инновационной, инвестиционной, социальной, финансовой, организационной, информационной, и др., быть предсказуемыми и неожиданными; один кризис способен вызывать цепную реакцию негативных явлений. Кризисы между собой тесно связаны и оказывают влияние на способность организации осуществлять те функции, ради которых оно создавалось, т.е. производить продукцию определенного вида, объема и качества [Хрусталев Е.Ю., 2010].

Кризис предприятия - это угроза существования бизнеса, и зачастую его итогом становится банкротство и ликвидация.

Понятие «кризис» (кризисная ситуация), таким образом, тесно связан с банкротством, как наиболее негативным этапом развития организации, при котором хозяйствующий субъект не способен осуществлять финансовое обеспечение своей хозяйственной деятельности. [Бланк И.А. , 2002].

Вместе с тем каждый из видов кризиса, несмотря на его опасность, глубину разрушительного действия, потенциальную угрозу дальнейшего ухудшения является управляемым, как любой кризис в экономической сфере. Компании могут испытывать влияние самых негативных факторов, быть подвержены кризисным воздействиям, однако при грамотно выработанной стратегии и эффективном антикризисном управлении не стать банкротом. Оптимальная система менеджмента может способствовать восстановлению жизнеспособности организации, ее сохранению в конечном итоге. Как вариант, возможно частичное или полное обновление организации. [Бусыгина Е.В., 2016].

Вместе с тем, современная практика использования терминов «кризис» и «банкротство» не учитывает детерминированной зависимости кризисных явлений и банкротства во времени с привязкой к структуре причинно-следственных связей. Несмотря на семантическую близость терминов «кризис» и «банкротство»в ряде исследований отмечаются принципиальные различия.

Если кризис- это внутреннее тяжелое положение, которое может быть вызвано самыми различными негативными факторами, то банкротство -это несостоятельность, сопровождающаяся прекращением платежей по долговым обязательствам [Любушин Н.П., Опарина О.И., 2007]. Рассматривая банкротство, как крайнее проявление кризиса, как заключительную стадию разрушительного процесса при этом нет оснований отождествлять банкротство и любой кризис, который может принимать самые различные формы, но при этом не приводить к ликвидации организации. Таким образом кризис, проявляющийся в самых различных сферах деятельности предприятия при этом непосредственно не связан с неспособностью выполнять свои платежные обязательства- как определяющего признака банкротства, а скорее может послужить толчком дальнейшего дестабилизирующего процесса.

\section{2. О понятиях «несостоятельность» и «банкротство»}

Еще большая смысловая неопределенность сложилась между понятиями «несостоятельность» и «банкротство». Российское законодательство о несостоятельности данные термины рассматривает как синонимы. Вопрос целесообразности и обоснованности такого терминологического дублирования вызвали непрекращающуюся научную дискуссию и единой точки зрения на их применение в настоящее время так и не сложилось. В частности, П.Д. Баренбойм, один из разработчиков закона 1992 г. о несостоятельности (банкротстве) предприятий, поддерживает законодательную позицию, «подкрепившую» термин «несостоятельность» более распространенным и понятным всем словом «банкротство» [Баренбойм П.Д., 1995]. Оппонентом данного высказывания выступил Г.А. Плиев., считая «Двойное употребление понятий «несостоятельность» и «банкротство» неоправданным. Смешение в российском праве рассматриваемых понятий «несостоятельность» и «банкротство» отрицательно влияет как на право- 
применительную практику, так и на восприятие общественностью этих не тождественных институтов». [ Плиев Г.А., 2005].

Не поддержали позицию на отождествление понятий Вайсблат Б.И. и Любушин Н.П., (2013): Столь вольное замещение терминов и употребление то одного, то другого возникло под влиянием законодательства стран англосаксонской системы права.[Вайсблат, Любушин, 2013]. Неприемлемость равнозначного толкования понятий высказали В.В. Зайцев, В.Ф. Попондопуло , В.В. Степанов, М.В. Телюкина, Л. Щенникова, ссылаясь на сложившиеся исторические традиции. На нежелательность использования разных терминов для обозначения одного правового явления указали в работах В.С Белых, А.А. Дубинчина, Л.М. Скуратовского, С.Ю. Чуча и др. Нельзя не согласиться с доминирующей точкой зрения большинства ученых, что произвольное использование понятий банкротство и несостоятельность для обозначения одного явления, не целесообразно как с юридической, так и с экономической позиции. Законодательно закреплённая позиция на синонимичность этих понятий представляется явной недоработкой ввиду отсутствия юридического объяснения понятий в законе и учета особенностей влияния процедур банкротства на экономические процессы должника.

Термины «банкротство» и «несостоятельность» имеют как юридическую, так и экономическую составляющие, пояснение, а четкое их разграничение необходимо для понимания протекающих кризисных процессов.

Наиболее общим понятием является категория «несостоятельность». Несостоятельность в широком значении- это такой уровень управления предприятием (фирмой, объектом хозяйствования), который не позволяет ему успешно осуществлять свои основные текущие функции; характеризуется количественными и качественными показателями несоответствующими устойчивому положению и не обеспечивающие возможность стабильного развития, а наличие претензий со стороны кредиторов к его финансовому состоянию и задержка обслуживания долговых обязательств, может привести к потери бизнеса. Несостоятельность значительно чаще трактуют как неудовлетворительное финансовое состояние организации и непосредственно связывается с неспособностью своевременно отвечать по своим обязательствам. Позиции российских ученых на такое понимание значения слова «несостоятельность» во многом определяют ход дальнейших рассуждений. Экономически несостоятельное предприятие является ненадежным, т.е. оно не способно удовлетворить требования кредиторов по оплате товаров (работ, услуг), обеспечить обязательные платежи в бюджет и внебюджетные фонды, в полном объеме покрыть производственные затраты. [Трифонов Ю.В., Мальцева Ю.А, 2015]. По мнению Г.Я. Кипермана, Б.С. Сурганова, несостоятельность (банкротство) - это финансовая несостоятельность организации, ее неспособность рассчитаться с кредиторами, вследствие бесхозяйственности, неквалифицированного управления, неспособности выдержать конкуренцию. [Киперман Г.Я., Сурганов Б.С., 1993].

Данный подход к определению несостоятельности, на наш взгляд, не раскрывает всей полноты и комплексности его экономического содержания, является ограниченным, поскольку уровень несостоятельности характеризуется исключительно в понимании взаимодействия с контрагентами, выступающими в качестве кредиторов. Понятие экономической несостоятельности гораздо шире и включает не только требования по финансовой стабильности и неизменному выполнению обязательств.

Экономическую несостоятельность целесообразно представляют в виде совокупности нескольких элементов: рыночной, производственной, финансовой несостоятельности.

Рыночная несостоятельность может характеризоваться низкой конкурентоспособностью компании, отсутствием рыночной самостоятельности вследствие неэффективной маркетинговой, сбытовой политики, игнорированием исследования конъюнктуры рынка, методов продвижения продукции и иными негативными факторами, тормозящими реализацию рыночных возможностей. Рыночную несостоятельность оценива- 
ется сокращением рынков сбыта, падением объема продаж, невозможностью восстановить свои рыночные позиции, а неизбежным итогом становятся проблемы с поддержанием устойчивого развития, с исполнением долговых обязательств. Несостоятельность отличает от кризиса степень разрушения рыночного механизма, который неизбежно влечет за собой неплатежеспособность и финансовую несостоятельность.

Производственная несостоятельность объединяет техническую и технологическую составляющие и понимается как неудовлетворительное состояние производственной базы предприятия, как неэффективное использование факторов производства, не обеспечивающих выпуск конкурентоспособной продукции. Критерием производственной несостоятельности является несоответствие производственных мощностей объему и качеству выпускаемой продукции, высокая доля амортизационных затрат в себестоимости, снижение оборачиваемости капитала, и как следствие -снижение прибыли.

Финансовая несостоятельность подразумевает необеспеченность финансовыми ресурсами, неэффективное распределение и использование имеющихся средств. Финансовая несостоятельность характеризуется неудовлетворительным уровнем ликвидности активов и баланса, несбалансированностью доходов и расходов, денежных и товарных потоков, недостаточной доходностью, низкой оборачиваемостью капитала, неплатежеспособностью, финансовой зависимостью, и др.

Рыночная, производственная несостоятельность тесно взаимосвязаны между собой и приводят к финансовой несостоятельности, характеризуя несоответствие целей, задач, стоящих перед субъектом хозяйствования и полученным уровнем финансового состояния и результатами от финансово-хозяйственной деятельности. Несмотря на приоритетность финансовой составляющей в обозначении экономической несостоятельности, не следует рассматривать ее только в контексте неплатёжеспособности. В понятии «несостоятельность» необходимо учитывать и ее правовую составляющую. Согласно Федеральному закону «О несостоятельности ( банкротстве)» от 26.10.2002 г. №127 Ф3 Несостоятельность - это признанная арбитражным судом неспособность должника в полном объеме удовлетворить требования кредиторов по денежным обязательствам о выплате выходных пособий и (или) об оплате труда лиц, работающих или работавших по трудовому договору, и (или) исполнить обязанность по уплате обязательных платежей.

И согласно ст. 3.ФЗ признаком несостоятельности, является не исполненные обязательства в течение трех месяцев с даты, когда они должны были быть исполнены. Таким образом, несостоятельность наступает только после назначения Арбитражным судом одной из процедур банкротства, подчеркивая правовую сторону процесса. Можно заметить также, что законодатель напрямую связывает несостоятельность с неплатежеспособностью, но не отождествляет их.

Как показала практика, «несостоятельность» часто используется в хозяйственном обиходе по отношению к организации еще до обращения кредиторов в арбитражный суд о признании ее банкротом, а , следовательно, компания- должник не является таковой. В этом случае использование термина является некорректным - правильнее было бы говорить о неплатежеспособности таких субъектов хозяйствования.

Неплатежеспособность -это чисто экономическое явление, характеризует невозможность расплатиться по своим обязательствам в конкретный момент времени, и вызывается отсутствием или недостаточностью у предприятия наличных средств в результате превышения заемного капитала над собственным. Сама по себе неплатёжеспособность не вызывает каких-либо правовых последствий для должника, но является сигналом, о неблагополучном финансовом положении предприятия. Неплатёжеспособность в зависимости от величины непогашенного долга и времени просроченных обязательств подразделяется на временную (или практическую) и абсолютную. 
Федеральный закон от 28.10.2002 г. №127 Ф3 «О несостоятельности» оценивает неплатёжеспособность, как факт прекращения исполнения должником части денежных обязательств или обязанностей по уплате обязательных платежей, вызванный недостаточностью денежных средств. Но, продолжая хозяйственную деятельность, предприятие-должник получает наличные средства как за реализованную продукцию, так и в счет погашения обязательств, являясь одновременно кредитором. В данном случае проблема разрешения временной (практической ) неплатежеспособности - вопрос времени и решается в текущем режиме предприятием самостоятельно. Следовательно, такая неспособность погасить возникшие обязательства, не должна рассматриваться в контексте несостоятельности. Когда же должник при обычном ведении дел не может выполнить свои обязательства в течение 3 месяцев с даты наступления платежа, то имеет место неплатежеспособность абсолютная по своему характеру. Именно абсолютная неплатежеспособность может повлечь правовые последствия, выступая основанием для инициирования арбитражного решения спора, и наиболее близка по экономическому содержанию к несостоятельности.

Не менее важным является логическое обоснование необходимости разграничения категорий банкротства и несостоятельности, что обусловлено сложившейся практикой оценки степени разрушительного состояния в деятельности компании, возможными последствиями, а также уточнением этапа процесса кризисного развития, когда несостоятельный должник уже своими силами не способен самостоятельно восстановить платежеспособность и рассчитаться по обязательствам.

Банкротство понимается, как крах, как прекращение деятельности, конец существования в прежней форме. Если несостоятельность - это не удовлетворительное финансовое состояние, зафиксированное в определённый момент времени, и которое только может завершиться банкротством при условии ухудшении финансовой ситуации, то «банкротство» - это такое состояние, при котором деятельность невозможна и нецелесообразна, а для соразмерного удовлетворения требований кредиторов , осуществляется ликвидация предприятия и продажа его имущества [Татаурова О.А., 2006]. Несостоятельность не обязательно приводит к банкротству- они разделены временем наступления. Четкую позицию в применении терминов в зависимости от конкретной экономической ситуации высказал Б.И. Колб, по мнению которого «...разница между несостоятельностью и банкротством состоит в том, что при несостоятельности должник еще может восстановить свою платежеспособность путем реализации процедуры внешнего управления , при банкротстве же к должнику применяется процедура конкурсного производства в целях соразмерного удовлетворения требований кредит оров в пределах имеющихся активов должника» [Колб Б.И, 1998] .

Крайняя степень неудовлетворительного положения организации, итогом которого становится банкротство, т.е. официально подтвержденная арбитражным судом невозможность реализации реабилитационных процедур и в соответствии с законодательством введение конкурсного производства, по результатам которого предприятиедолжник подлежит ликвидации- таково принципиальное толкование банкротства, которому придерживается большинство исследователей.

Рассмотрев содержание и практику применения терминов «несостоятельность» и «банкротство», следует отметить объединяющее их начало: использование каждого по отношению к должнику требует решения арбитражного суда. Подход, при котором должник, в отношении которого возбуждены процедуры банкротства, считается несостоятельным, а после судебного решения о ликвидации, признается банкротом, наиболее точно отражает отличительную особенность рассматриваемых дефиниций.

Несмотря на кажущуюся синонимичность понятий, необходимо учитывать строгую логическую последовательность развития негативных событий. Формирующийся комплекс проблем и усиливающиеся факторы текущего неблагополучия организации приводят к кризисному состоянию и могут вызвать неплатёжеспособность- 
неспособность рассчитываться по своим обязательствам. Переход к абсолютной неплатёжеспособности, когда объем просроченных непокрытых долгов становится непосильным для самостоятельного их погашения и в случае обращения кредиторов в арбитражный суд, приводит к несостоятельности.

На соподчиненность понятий «несостоятельность» и «банкротство» указывали Вайсблат Б.И., Любушин Н.П: «Следует полагать, что наиболее правильной является точка зрения о существовании определенной иерархии, ибо процесс начинается с выявления несостоятельности организации. Если же организация теряет всякие перспективы рассчитаться с кредиторами, то должник переходит в новое качество-становится несостоятельным. Последняя третья стадия и есть качественное состояние- банкротство» [Вайсблат Б.И., Любушин Н.П., 2013].

\section{ЗАКЛЮЧЕНИЕ}

Рассмотренные особенности применения понятийного аппарата, характеризующего процесс нарастания кризисных явлений, приводящих к банкротству, дают возможность наиболее точно использовать такие дефиниции, как кризис, неплатёжеспособность, несостоятельность, банкротство, позволяют обеспечить единство в оценке негативных явлений, стадии деструктивного развития, избежать неоправданной подмены экономических и правовых понятий, их смешения, при необходимости объективно охарактеризовать последовательность принятия антикризисных мероприятий и возможные последствия возникновения этих явлений.

$$
* * *
$$

1. Адизес И.К. Управление жизненным циклом корпорации. СПб.: Изд. Интер, 2007

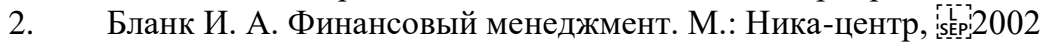

3. Баренбойм П.Д. Правовые основы банкротства. М.: Изд. Белые альвы, 1995

4. Бусыгина Е.В. Основные черты управления персоналом в кризисной ситуации // Современные научные исследования и инновации. 2016. № 1. С. 390-393

5. Вайсблат Б.И., Любушин Н.П. Оценка риска несостоятельности организаций // Экономический анализ: теория и практика. 2013. № 42. С. 345-358

6. Киперман, Г.Я. Сурганов. Я.Б. Популярный экономический словарь - М.: Экономика, 1993

7. Любушин Н.П., Опарина О.И. Анализ общего и специфического в понятиях «кризис», «несостоятельность», «банкротство» // Экономический анализ: теория и практика. 2007. № 9. С. 2-8

8. Маренков Н. Л. Антикризисное управление. Ростов на Дону.: Изд. Феникс, 2004

9. Плиев Г.А. Гражданско-правовой механизм предупреждения несостоятельности (банкротства) юридических лиц: автореф.дис......кан. юрид. Наук. М, 2005

10. Татаурова О. А. Методические основы системы оценки несостоятельности юридических лиц. // Научные труды Вольного экономического общества России. Т. 69. 2006. С. 521-525

11. Трифонов Ю.В. Мальцева Ю.А. Динамический подход при анализе экономической состоятельности предприятия //Экономика и предпринимательство 2015. № 4 (ч.1). С. 558-561

12. Хрусталев Е.Ю. Экономическая безопасность наукоемкого предприятия: методы диагностики и оценки // Национальные интересы: приоритеты и безопасность. 2013. 13(70). С. 51-58

$$
* * *
$$

1. Adizes I. K. life cycle Management of the Corporation. SPb.: Ed. Inter, 2007

2. Blank I. A. Financial management. M.: Nika-center, 2002

3. Barenboim p. D. legal basis of bankruptcy. M.: Ed. White Alva, 1995

4. Busygina E. V. the Main features of personnel management in a crisis situation / / Modern research and innovation. 2016. No. 1. P. 390-393

5. Weisblat B. I., Lyubushin N. P. Assessment of the risk of insolvency of organizations / / Economic analysis: theory and practice. 2013. No. 42. S. 345-358

6. Kiperman, G. I. Surganov. J. B., a Popular dictionary of Economics - M.: Economics, 1993

7. Lyubushin N. P. Oparina O. I. analysis of the General and specific in terms of "crisis", "insolvency", "bankruptcy" / / Economic analysis: theory and practice. 2007. No. 9. S. 2-8

8. Marenkov N. L. Crisis management. Rostov-on-don.: Ed. Phoenix, 2004

9. Pliev G. A. Civil-legal mechanism of preventing insolvency (bankruptcy) of legal entities: autoref.dis.....kan. the faculty of law. Sciences'. M, 2005 
10. Tataurova O. A. Methodical bases of system of an assessment of insolvency of legal entities / / Scientific works of Free economic society of Russia. Vol. 69. 2006. P. 521-525

11. Trifonov Yu. V. Maltseva Yu.a. Dynamic approach in the analysis of the economic viability of an enterprise //Economics and entrepreneurship 2015. № 4 (part 1). P. 558-561

12. Khrustalev E. Y. Economic security of science-intensive enterprises: methods of diagnosis and assessment // National interests: priorities and security. 2013. 13 (70). P. 51-58

Толпегина О.А., к.э.н, доиент кафедpы, tolpegina_Olga@mail.ru

Tolpegina O.,Ph. D. in Economics, associate Professor,Tolpegina_Olga@mail.ru 